\title{
Pentosan polysulfate inhibits atherosclerosis in Watanabe heritable hyperlipidemic rabbits: differential modulation of metalloproteinase-2 and -9
}

\author{
Enrico Lupia ${ }^{1,2, *}$, Feng Zheng ${ }^{3, *}$, Fabrizio Grosjean ${ }^{1,4}$, Ivan Tack ${ }^{5}$, Sophie Doublier ${ }^{6}$, Sharon J Elliot ${ }^{7}$, \\ Helen Vlassara ${ }^{1}$ and Gary E Striker ${ }^{1}$
}

Pentosan polysulfate (PPS), a heparinoid compound essentially devoid of anticoagulant activity, modulates cell growth and decreases inflammation. We investigated the effect of PPS on the progression of established atherosclerosis in Watanabe heritable hyperlipidemic (WHHL) rabbits. After severe atherosclerosis developed on an atherogenic diet, WHHL rabbits were treated with oral PPS or tap water for 1 month. The aortic intima-to-media ratio and macrophage infiltration were reduced, plaque collagen content was increased, and plaque fibrous caps were preserved by PPS treatment. Plasma lipid levels and post-heparin hepatic lipase activity remained unchanged. However, net collagenolytic activity in aortic extracts was decreased, and the levels of matrix metalloproteinase (MMP)-2 and tissue inhibitor of metalloproteinase (TIMP) activity were increased by PPS. Moreover, PPS treatment decreased tumor necrosis factor $\alpha$ $(\mathrm{TNF} \alpha)$-stimulated proinflammatory responses, in particular activation of nuclear factor- $\kappa \mathrm{B}$ and $\mathrm{p} 38$, and activation of MMPs in macrophages. In conclusion, oral PPS treatment prevents progression of established atherosclerosis in WHHL rabbits. This effect may be partially mediated by increased MMP-2 and TIMP activities in the aortic wall and reduced TNF $\alpha$-stimulated inflammation and MMP activation in macrophages. Thus, PPS may be a useful agent in inhibiting the progression of atherosclerosis.

Laboratory Investigation (2012) 92, 236-245; doi:10.1038/labinvest.2011.154; published online 31 October 2011

KEYWORDS: atherosclerosis; heparin-like; lipids; macrophages; metalloproteinases; TNF $\alpha$

Heparin and heparin-like molecules decrease cell proliferation, increase net extracellular matrix production in several cell types, and decrease the secretion of matrix metalloproteinases (MMPs) in vitro. ${ }^{1-4}$ The accumulation of macrophage-derived foam cells in atherosclerotic plaques correlates with increased release of tumor necrosis factor $\alpha(\mathrm{TNF} \alpha)$ and MMPs ${ }^{5,6}$ which may influence vascular remodeling and plaque rupture, thus precipitating acute complications such as unstable angina and acute myocardial infarction. ${ }^{7-11}$

Pentosan polysulfate (PPS) is an oral heparinoid-like preparation essentially devoid of anticoagulant activity and is approved for the treatment of interstitial cystitis. ${ }^{12} \mathrm{We}$ previously found that PPS treatment prevents the development of chronic inflammatory lesions and histological lesions in $5 / 6$ nephrectomized rats. ${ }^{13}$ We also found that PPS decreases mesangial cell proliferation in vitro, ${ }^{14}$ human vascular smooth muscle cells derived from vascular grafts, ${ }^{15}$ and smooth muscle cells obtained from the prostate interstitium. ${ }^{16}$ In addition, PPS increases MMP-2 secretion and stimulates the production of tissue inhibitor of metalloproteinase (TIMP)-1 and the shedding of TIMP-3 from the surface of mesangial cells. ${ }^{14}$

In this study, we investigated the effect of oral treatment with PPS on the progression of established atherosclerotic lesions in Watanabe heritable hyperlipidemic (WHHL) rabbits. ${ }^{17}$ We examined the effect of PPS on established atherosclerotic lesions as the most clinically relevant and the most stringent test of PPS efficacy.

\footnotetext{
${ }^{1}$ Department of Geriatrics, Mount Sinai School of Medicine, New York, NY, USA; ${ }^{2}$ Department of Clinical Pathophysiology, University of Turin, Turin, Italy; ${ }^{3}$ Department of Nephrology, Dongfang Hospital, Fujian Medical University, Fuzhou, Fijian, China; ${ }^{4}$ Units of Nephrology, Dialysis and Transplantation, Policlinico San Matteo, University of Pavia, Pavia, Italy; ${ }^{5}$ Hopital de Rangueil, Toulouse, France; ${ }^{6}$ Department of Genetics, Biology and Biochemistry, University of Turin, Turin, Italy and ${ }^{7}$ Department of Surgery, University of Miami School of Medicine, Miami, FL, USA

Correspondence: Dr GE Striker, MD, Department of Geriatrics, Mount Sinai School of Medicine, 1 Gustave Levy Place, New York, NY 10029, USA. E-mail: gary.striker@mssm.edu

*These two authors contributed equally to this work. 


\section{MATERIALS AND METHODS Reagents}

PPS was from IVAX Corp. (Miami, FL, USA) or SWATI Spentose (Mumbai, India), tissue culture reagents were from Gibco BRL (Grand Island, NY, USA), 10\% gelatin polyacrylamide zymography gels from Novex (San Diego, CA, USA), the First Strand cDNA synthesis kit from Boehringer Mannheim (Indianapolis, IN, USA), and other reagents were from Sigma Chemical (St Louis, MO, USA).

\section{Study Protocol}

The 3-month-old female WHHL rabbits, from the Institute for Experimental Animals, Kobe University School of Medicine, ${ }^{17}$ were fed a standard chow diet supplemented with 0.5\% cholesterol (high cholesterol (HC)-diet,) for the duration of the experiment. Preliminary experiments showed that severe atherosclerotic lesions developed by 45 days and that a PPS dose of $30 \mathrm{mg} / \mathrm{kg}$ of body weight (BW) was the maximally tolerated dose without side effects. A total of 20 rabbits were randomized into two groups after 45 days of the HCdiet. For the next 30 days both groups were maintained on the HC-diet, but one group received PPS $(30 \mathrm{mg} / \mathrm{kg} \mathrm{BW}$ daily) in the drinking water and the other received only tap water. Hemoglobin levels remained unchanged and the feces remained guaiac negative. The rabbits were killed by anesthesia with ketamine hydrochloride and xylazine (60 and $6 \mathrm{mg} / \mathrm{kg} \mathrm{BW}$, respectively). Five per group were perfusionfixed with $4 \%$ phosphate-buffered formaldehyde solution. The remaining five per group were anesthetized, perfused with saline, and aortic arch ring sections were snap-frozen in liquid nitrogen. Aortas were removed from five additional untreated 4.5-month-old WHHL rabbits that had been fed the HC-diet for 45 days, as baseline controls, and were similarly processed. Animal care and procedures were in accordance with American Association for Accreditation for Laboratory Animal Care and the National Institutes of Health guidelines.

\section{Plasma Lipid and Lipoprotein Analyses}

After a 12-h fast, blood was drawn into EDTA tubes at baseline, every 2 weeks, and at study end. Total plasma cholesterol and triglyceride (Sigma), and unesterified cholesterol and phospholipids were determined using enzymatic methods on a Hitachi 911 Autoanalyzer (Boehringer Mannheim). Post-heparin hepatic lipase activity was determined as described. $^{18}$

\section{Morphological Analysis and Immunohistochemistry}

Aortic atherosclerosis was evaluated as percent intimal lesion area (lesion surface area/entire surface area) between the aortic arch origin and renal arteries. The intima-to-media ratio (I/M ratio) was measured by computer-aided morphometric analysis in three consecutive hematoxylin- and eosinstained cross-sections: aortic arch, abdominal aorta, and origin of the renal arteries. The thickest atherosclerotic lesions were selected for the analysis to avoid errors due to the heterogeneity of lesions. ${ }^{19}$ The areas occupied by macrophages and collagen were measured by computer-aided morphometry on sections stained with RAM-11 antibody (DAKO Corporation) or Sirius red.

\section{Cell Preparation and Experimental Conditions}

Human pro-monocytic U937 cells $\left(5 \times 10^{6}\right.$ cells per $\left.\mathrm{ml}\right)$ in RPMI medium supplemented with 10\% FBS were stimulated with $10 \mathrm{ng} / \mathrm{ml} \mathrm{TNF} \alpha$, in increasing concentrations of PPS $(10-100 \mu \mathrm{g} / \mathrm{ml})$ or heparin $(10-100 \mu \mathrm{g} / \mathrm{ml})$, incubated at $37^{\circ} \mathrm{C}$ for $3 \mathrm{~h}$, and then in $0.1 \%$ BSA-serum-free medium for 16-18 h. Supernatants were stored at $-80^{\circ} \mathrm{C}$. Human peripheral blood monocytes (PBMs) were isolated as described ${ }^{20}$ and maintained in medium 199 supplemented with $2 \%$ human serum for differentiation into macrophages. ${ }^{21}$

Peritoneal macrophages were used to assess the effect of in vivo treatment with PPS on MMP activity. Before cell preparation, 12-week-old $\mathrm{C} 57 \mathrm{Bl} / 6 \mathrm{~J}$ mice were treated with $100 \mathrm{mg} / \mathrm{kg}$ BW PPS orally (by gavage) for 5-6 days. Peritoneal macrophages were collected by extensive washing of the peritoneal cavity with 0.1 BSA-RPMI medium 3 days after intra-peritoneal injection of $1.5 \mathrm{ml}$ thioglycollate, centrifuged at $200 \mathrm{~g}$ for $5 \mathrm{~min}$, and suspended at $0.2 \times 10^{6} / \mathrm{ml}$ in $10 \%$ FBS-RPMI in 24-well plate. ${ }^{21}$ Harvested macrophages were further purified by adherence to plastic dishes for $2 \mathrm{~h}$ at $37^{\circ} \mathrm{C}$ in $5 \% \mathrm{CO}_{2}$, followed by three washes with $0.1 \%$ BSA-RPMI medium, and then stimulated with TNF $\alpha$ as described above.

\section{Zymography and Reverse Zymography}

Briefly, aortic segments were homogenized, extracted in RIPA buffer, centrifuged, and soluble extracts were harvested. For in vitro experiments, cell supernatants were normalized for cell number. Aortic extracts and conditioned media, mixed with sample buffer, were loaded onto a $10 \%$ gelatin polyacrylamide gel. $^{22}$ For reverse zymography, samples were loaded onto a $15 \%$ gelatin polyacrylamide gel containing $0.5 \%$ porcine gelatin and $6 \mu \mathrm{g}$ recombinant gelatinase $\mathrm{A}^{14}$

\section{Evaluation of Net MMP Activity}

MMP-2/MMP-9 net activity in aortic extracts was evaluated using a synthetic colorimetric substrate (Ac-Pro-Leu-Gly(2-mercapto-4-methylpentanoyl)-Leu-Gly-OEt; Calbiochem, Cambridge, MA, USA). Recombinant gelatinase A and B were used as standards.

\section{NF- $\kappa$ B Activity in RAW Cells}

RAW cells $\left(1 \times 10^{7}\right.$ per dish) were treated with $\mathrm{TNF} \alpha(10 \mathrm{ng} / \mathrm{ml})$, with or without PPS $(400 \mu \mathrm{g} / \mathrm{ml})$ for 15,30 , or $60 \mathrm{~min}$. Phosphorylated and total JNK, I $\kappa \mathrm{B}$, and p38 were determined by western blots. The same membrane was re-probed with $\beta$-actin to ensure equal protein loading. Experiments were repeated three times. The intensity of protein bands was quantitated by densitometry. NF- $\kappa \mathrm{B}$ transcription activity was examined by transfecting macrophages with an NF- $\kappa \mathrm{B}$ 
luciferase reporter together with a $\beta$-gal plasmid using a lipofectamine transfection kit from Promega, according to the manufacturer's recommendations. Controls included cells transfected with IKK and I $\kappa$ B to demonstrate that NF- $\kappa$ B transcription was regulated by activators and suppressors, to verify that the assays were functioning properly. TNF $\alpha$ was added to reporter-transfected cells together with or without PPS. Experiments were repeated twice.

\section{Statistical Analysis}

Data are presented as mean \pm s.e.m. Differences among multiple groups were analyzed by one-way analysis of variance (ANOVA) in combination with Bonferroni's multiple comparison test. Lipid levels were expressed as percent of the basal values for each individual animal and analyzed by using repeated measures by ANOVA. Where appropriate, statistical differences were assessed using Student's $t$-test (Prism, GraphPad 3.02, San Diego, CA, USA). A P-value of $<0.05$ was considered significant.

\section{RESULTS}

\section{Progression of Established Atherosclerotic Lesions}

The progression of established atherosclerosis induced by HC-diet in WHHL rabbits was modestly, but significantly decreased by PPS treatment (Figure 1a and b). In the watertreated controls, the aortic surface was irregular owing to the presence of multiple plaques of varying size. In contrast, the aortic surface in the PPS-treated group was relatively smooth and glistening and the plaques had a smooth flattened contour. Moreover, the aortic wall was irregularly thickened and was less pliable in the water-treated group compared with the PPS-treated group. Analysis of the intimal surface showed that the percent surface area of the intima occupied by lesions in the PPS-treated group was reduced by approximately 10\% compared with the watertreated controls (Figure 1c). Microscopic examination of the aorta in the PPS-treated group showed that the plaques were thinner and contained fewer foam cells, no increase in the number of the cells in the intima or media, and a
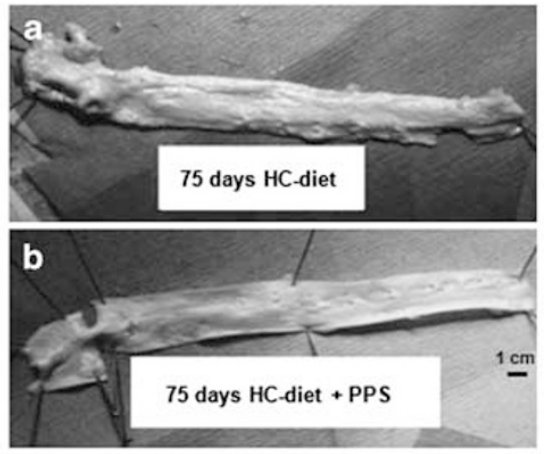

C
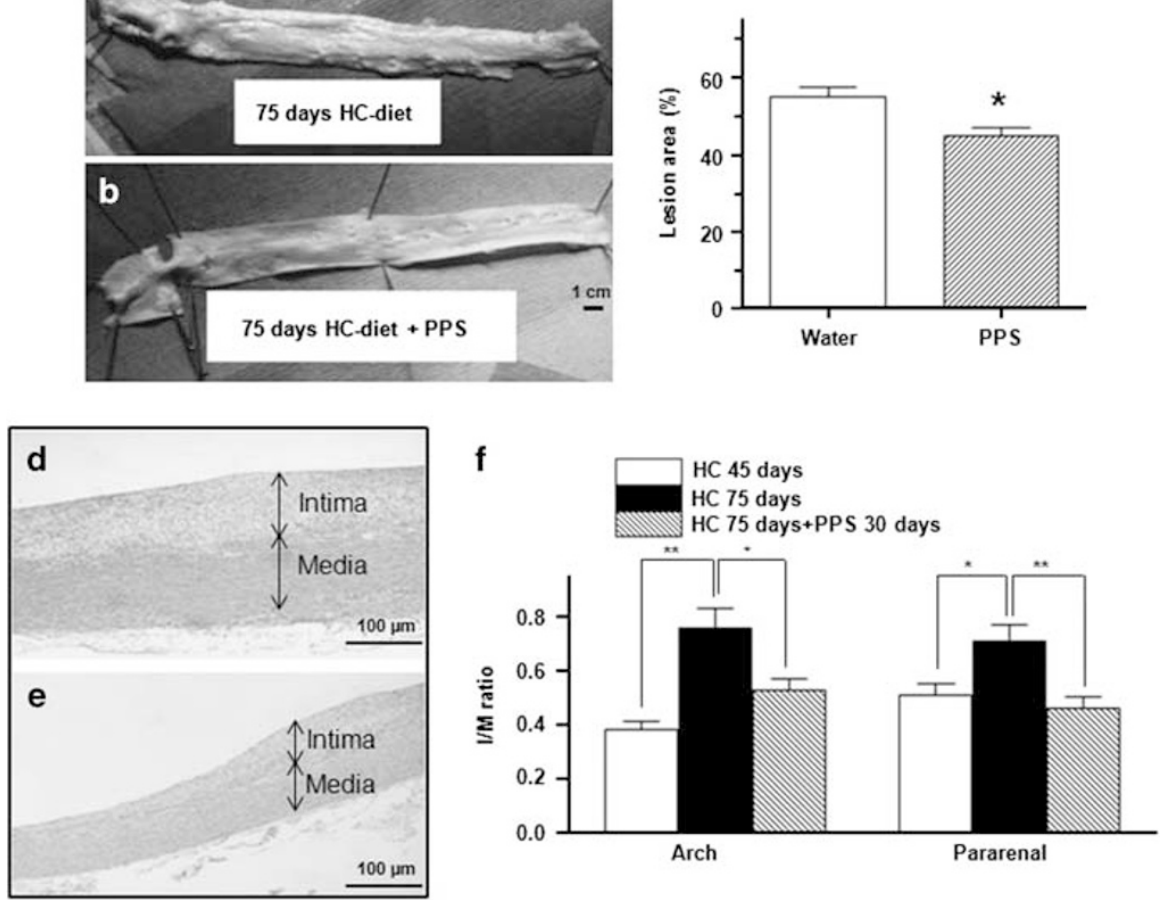

Figure 1 Analysis of atherosclerotic lesions in Watanabe heritable hyperlipidemic (WHHL) rabbits. Animals were fed a high-cholesterol (HC)-diet for 75 days. After 45 days, they were randomized into two groups, one receiving pentosan polysulfate (PPS) ( $30 \mathrm{mg} / \mathrm{kg}$ body weight (BW) daily) in the drinking water and the other receiving tap water only, as detailed in the Materials and Methods section. (a and b) Representative photographs of aortic inner surface after 75 days of an HC-diet. Images were obtained from aortas freshly dissected from rabbits perfusion-fixed with $4 \%$ phosphate-buffered formaldehyde solution (five per group). (a) HC-diet for 75 days plus tap water. (b) HC-diet for 75 days, and on day 45, PPS was added to the drinking water and continued for the remaining 30 days. (c) Quantification of atherosclerotic lesions in WHHL rabbits by en face analysis in WHHL rabbits. Aortic atherosclerosis was evaluated as percent intimal lesion area (lesion surface area/entire surface area) between the aortic arch origin and renal arteries. ${ }^{\star} P<0.05$. (d and e) Representative photographs of hematoxylin- and eosin-stained cross-sections of aortic arch obtained from WHHL rabbits after 75 days on an HC-diet. Aortic arch cross-sections were obtained from aortas freshly dissected from rabbits perfusion-fixed with $4 \%$ phosphate-buffered formaldehyde solution (five per group). (d) HC-diet for 75 days plus tap water. (e) HC-diet for 75 days, and on day 45, PPS was added to the drinking water and continued for the remaining 30 days. (f) Intima-to-media (I/M) ratio of aortic cross-sections. The I/M ratio was measured by computer-aided morphometric analysis in the aortic arch and near the origin of the renal arteries. ${ }^{\star} P<0.05,{ }^{*} P<0.01$. 
reduction in the $\mathrm{I} / \mathrm{M}$ ratio (Figure $1 \mathrm{~d}$ and e). The calculated $\mathrm{I} / \mathrm{M}$ ratio at the aortic arch and in the abdominal aorta, close to the emergence of the renal arteries, was significantly increased from 45 to 75 days in WHHL rabbits fed an HC-diet (Figure 1f, black bars). The I/M ratio in PPStreated animals was significantly lower (Figure 1f, hatched bars) compared with untreated controls. Moreover, the $\mathrm{I} / \mathrm{M}$ ratio in rabbits fed an $\mathrm{HC}$-diet for 45 days and treated with oral PPS for an additional 30 days was not significantly different from that measured in WHHL rabbits fed an HC-diet for 45 days (baseline), suggesting that the lesions did not progress during the PPS treatment period (Figure 1f, white bars).

The plaques in the water-treated group contained a dense infiltrate of macrophages and lacked a fibrous cap (Figure 2a and $\mathrm{d}$ ). The plaques in the PPS-treated group had fewer macrophages and were covered by an organized fibrous cap (Figure $2 \mathrm{~b}$ and e). The plaque area containing macrophages/total plaque area was decreased in PPS-treated rabbits $(36 \pm 2 \%)$ vs untreated controls $(52 \pm 6 \%, P<0.05$; Figure 2c).
Total collagen deposition within the atheroma, by Sirius red staining, showed significantly more collagen in PPStreated rabbits, especially on the luminal surface of plaques $(47 \pm 3 \%) v s$ controls $(31 \pm 3 \%, P<0.01$; Figure $2 \mathrm{~d}-\mathrm{f})$.

\section{Plasma Lipids}

Rabbits on HC-diet for 45 days had increased plasma total $(240 \pm 18 \%)$ and free $(377 \pm 62 \%)$ cholesterol, as well as phospholipid $(221 \pm 33 \%)$ concentrations, while triglyceride concentrations decreased (36 $\pm 9 \%)$ (Table 1). The levels were not further increased after an additional 30 days on the atherogenic diet. There were no differences in lipid levels between PPS- and water-treated animals (Table 1), although a trend towards a reduction of lipid levels after PPS treatment was observed. Post-heparin hepatic lipase activity at the end of treatment period revealed no differences between treatment groups (data not shown).

\section{MMP and TIMP Activities in Aortic Extracts Ex Vivo}

MMP activity was assessed in extracts of aortic arch ring sections snap-frozen in liquid nitrogen using either a

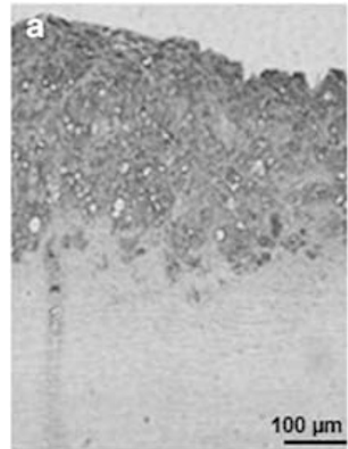

Control

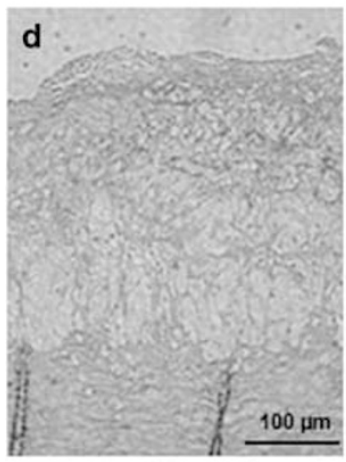

Control

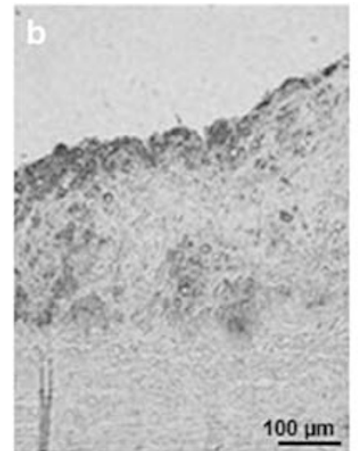

PPS

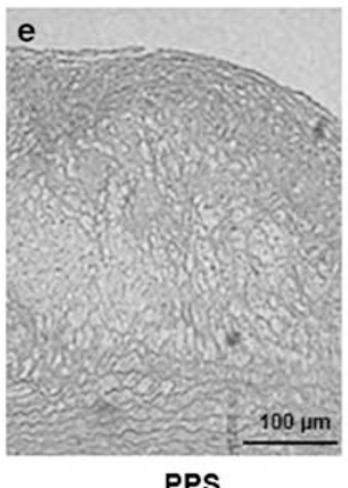

Figure 2 Analysis of macrophage infiltration and collagen content in atherosclerotic lesions from Watanabe heritable hyperlipidemic (WHHL) rabbits. Animals were fed a high cholesterol (HC)-diet for 75 days. After 45 days, they were randomized into two groups, one receiving pentosan polysulfate (PPS) (30 mg/kg body weight (BW) daily) in the drinking water and the other receiving tap water only, as detailed in the Materials and Methods section. (a and b) Representative micrographs of aortic arch cross-sections stained with RAM-11 antibody to detect infiltrating macrophages. (a) HC-diet for 75 days. (b) HC-diet for 75 days, and on day 45, PPS was added and continued for the remaining 30 days. (c) Quantification of the area occupied by macrophages as measured by computer-aided morphometry in aortic arch cross-sections stained with RAM-11 antibody. (d and e) Representative micrographs of aortic arch cross-sections stained with Sirius red to identify collagen. (d) HC-diet for 75 days. (e) HC-diet for 75 days, and on day 45, PPS was added and continued for the remaining 30 days. (f) Quantification of the area occupied by collagen as measured by computer-aided morphometry in aortic arch cross-sections stained with Sirius red. ${ }^{*} P<0.05$. 
Table 1 Plasma lipid concentrations

Baseline 45 days HC-diet 75 days HC-diet

Total cholesterol (mg/dl)

$\begin{array}{llll}\text { Control (water-treated) } & 846 \pm 68 & 1979 \pm 78 & 1894 \pm 57 \\ \text { PPS-treated } & 901 \pm 50 & 2133 \pm 85 & 1565 \pm 212\end{array}$

Free cholesterol $(\mathrm{mg} / \mathrm{dl})$

$\begin{array}{lrrr}\text { Control (water-treated) } & 251 \pm 22 & 963 \pm 127 & 967 \pm 93 \\ \text { PPS-treated } & 283 \pm 13 & 1039 \pm 129 & 785 \pm 93\end{array}$

Triglycerides ( $m g / d l)$

$\begin{array}{llll}\text { Control (water-treated) } & 750 \pm 120 & 238 \pm 610 & 275 \pm 69 \\ \text { PPS-treated } & 763 \pm 72 & 331 \pm 87 & 184 \pm 30\end{array}$

Phospholipids (mg/dl)

$\begin{array}{lllr}\text { Control (water-treated) } & 504 \pm 42 & 1118 \pm 130 & 1070 \pm 102 \\ \text { PPS-treated } & 575 \pm 26 & 1241 \pm 143 & 878 \pm 108\end{array}$

Abbreviations: PPS, Pentosane polysulfate; WHHL, Watanabe heritable hyperlipidemic; BW, body weight.

Plasma lipid levels were measured at baseline ( 3 months of age) and after 45 and 75 days on a high cholesterol (HC)-diet. After 45 days on an HC-diet, WHHL rabbits were randomized to receive tap water (Control) or PPS ( $30 \mu \mathrm{g} / \mathrm{kg}$ BW daily) added to the drinking water for the next 30 days, as detailed in the Materials and Methods section. Data are expressed as $\mathrm{mg} / \mathrm{dl}$, mean \pm s.e.m. of five animals in each group.

synthetic colorimetric substrate and by zymography. Net MMP-2/MMP-9 activity, as assessed by a synthetic colorimetric substrate, was reduced in WHHL rabbits treated with PPS compared with water-treated animals by $28 \pm 4 \%$ $(P<0.05)$. MMP-2 activity, evaluated by zymography, was significantly increased in aortic extracts obtained from PPStreated WHHL rabbits (Figure $3 \mathrm{a}$ and $\mathrm{b}$ ).

The activities of TIMPs, specific endogenous inhibitors of MMPs, were determined by reverse zymography. The activities of TIMP-1, -2, and -3 after 75 days on the HC-diet did not differ from those measured at 45 days (Figure $3 \mathrm{c}$ and $\mathrm{d}$ ), whereas treatment with PPS induced a marked increase in the activity of these TIMPs at 75 days (Figure $3 \mathrm{c}$ and d).

\section{MMP Activity in Monocytes In Vitro and Ex Vivo}

Since increased MMP activity in monocyte-macrophages may correlate with the development of acute complications such as plaque rupture and thrombosis, ${ }^{5-11}$ we evaluated the effect of PPS on MMP activity in U937 cells, human PBMs, and murine peritoneal elicited macrophages by zymography. Unstimulated U937 cells expressed only MMP-2 activity. However, after the addition of TNF $\alpha$, they expressed both MMP-2 and MMP-9 activities, which are characteristics of the in vitro macrophage phenotype (Figure 4a). ${ }^{23}$ PPS treatment decreased MMP-2 activity by $45 \pm 10 \%(P<0.01)$ in unstimulated U937 cells (Figure 4b), as did heparin treatment (Figure 4a). Both MMP-2 $(38 \pm 12 \% ; P<0.05)$ and MMP-9 (52 $\pm 11 \% ; P<0.01)$ activities in U937 cells stimulated with $10 \mathrm{ng} / \mathrm{ml} \mathrm{TNF} \alpha$ (Figure $4 \mathrm{a}$ and c) were reduced by PPS treatment. The PPS effect was detectable at $25 \mu \mathrm{g} / \mathrm{ml}$ and was maximal at $75-100 \mu \mathrm{g} / \mathrm{ml}$ (data not shown).

PPS inhibited MMP production by human PBMs after $\mathrm{TNF} \alpha$ stimulation (Figure $4 \mathrm{~d}-\mathrm{f}$ ). PPS had no effect on cell viability, as assessed by Trypan blue staining (data not shown).

Murine peritoneal-elicited macrophages were used to assess the effect of in vivo treatment with PPS on MMP activity. Peritoneal macrophages derived from mice treated orally with PPS for the previous 5-6 days and stimulated in vitro with $10 \mathrm{ng} / \mathrm{ml} \mathrm{TNF} \alpha$ showed a marked decrease in MMP-2 and MMP-9 activities, when compared with macrophages from mice treated with water (Figure $4 \mathrm{~g}$ ), showing the efficacy in vivo of PPS treatment on MMP activity.

\section{TNF $\alpha$-Induced NF- $\kappa B$ and MAPK Activation}

Since the proinflammatory actions of TNF $\alpha$ are predominantly mediated by the NF- $\kappa \mathrm{B}$ and MAPK pathways, we examined the effects of PPS on TNF $\alpha$-stimulated NF- $\kappa \mathrm{B}$ and MAPK activation. Treatment of RAW cells with TNF $\alpha$ quickly induced the phosphorylation of $\mathrm{I} \kappa \mathrm{B}$, JNK, and p38 (Figure $5 a-d)$. The presence of PPS caused a $\sim 50 \%$ reduction in $\mathrm{TNF} \alpha$-stimulated $\mathrm{I} \kappa \mathrm{B}$ and $\mathrm{p} 38$ phosphorylation, while it had no significant effect on TNF $\alpha$-induced JNK phosphorylation. PPS decreased the stimulation of NF- $\kappa \mathrm{B}$ transcription activity by TNF $\alpha$ in a dose-dependent manner (Figure 5e).

\section{DISCUSSION}

This study shows that oral PPS prevents the progression of established atherosclerotic lesions in aortas of WHHL rabbits fed a high-fat diet. This effect was not due to an anticoagulant action, because PPS has only $1 / 15$ th the anticoagulant activity of heparin, and bleeding was not observed. In addition, the reduction of atherosclerotic lesions after PPS treatment did not appear to be related to changes in plasma lipid levels, as total and free cholesterol, triglyceride, and phospholipid concentrations did not differ between PPStreated and control groups. Moreover, no difference in the activity of post-heparin hepatic lipase was detected. In our study, we randomly divided the animals into two groups after 45 days on the HC-diet, one received water and the other received PPS for the next 30 days. Plasma lipids, analyzed separately after randomization, revealed that the values measured in the PPS group at baseline as well as at 45 days showed a trend to be more elevated than in the control group. We have no clear explanation for this issue; however, because also of small numbers, we cannot exclude that the trend toward lower circulating lipoproteins seen in PPStreated animals after 75 days may also contribute to the antiatherosclerotic effects observed with PPS in vivo. Although we did not measure blood pressure in this study, others have studied this is several different models and shown that PPS 

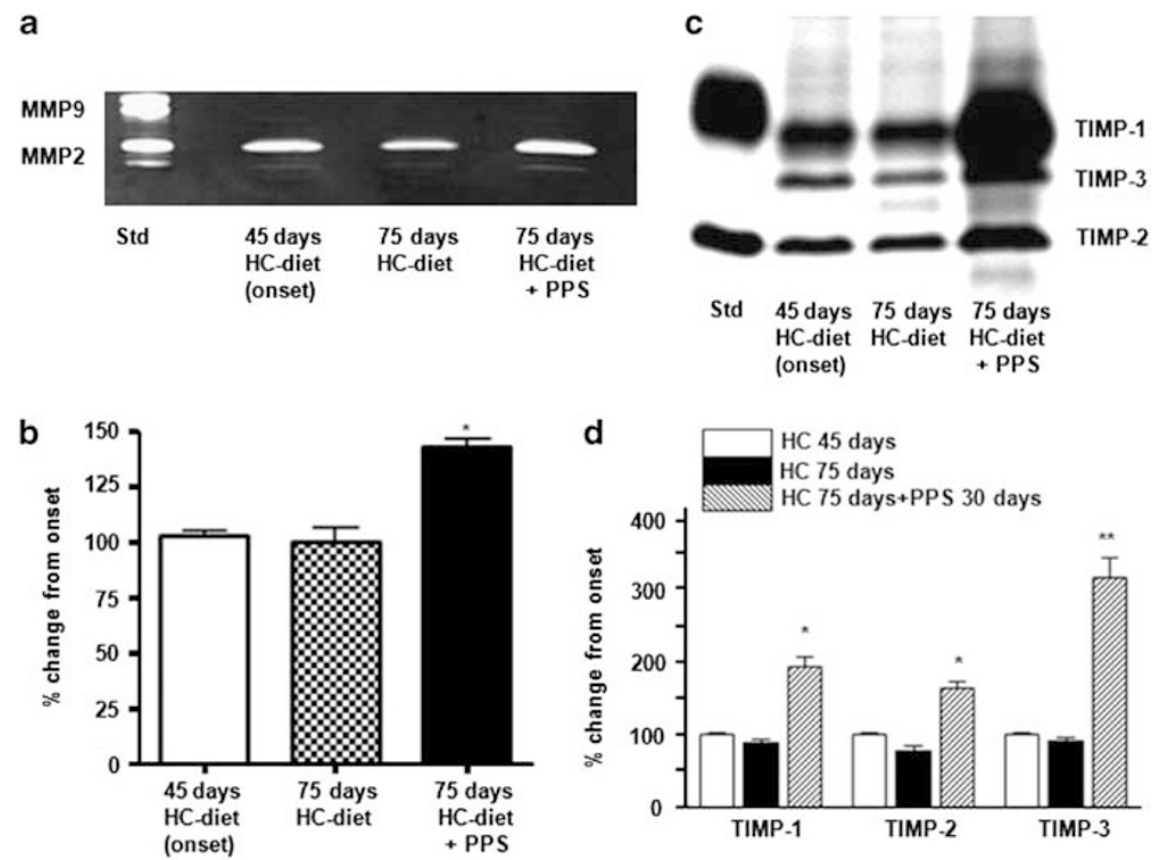

Figure 3 Matrix metalloproteinase (MMP) activity and tissue inhibitor of metalloproteinase (TIMP) levels in aortic extracts from Watanabe heritable hyperlipidemic (WHHL) rabbits. WHHL rabbits were fed a high cholesterol (HC)-diet for 75 days. After 45 days, they were randomized into two groups, one receiving pentosan polysulfate (PPS) $(30 \mathrm{mg} / \mathrm{kg}$ body weight (BW) daily) in the drinking water and the other receiving tap water only, as detailed in the Materials and Methods section. After 75 days, five animals per group were anesthetized, perfused with saline, and aortic arch ring sections were snap-frozen in liquid nitrogen. Aortas were removed from five additional untreated 4.5-month-old WHHL rabbits that had been fed the HC-diet for 45 days, as baseline controls. (a) Representative zymography of aortic extracts obtained from WHHL rabbits on an HC-diet. (b) Quantification of MMP-2 activity by densitometric analysis in aortic extracts obtained from WHHL rabbits on an HC-diet $\left(n=3\right.$ experiments, $\left.{ }^{*} P<0.05\right)$. (c) Representative reverse zymographic analysis of TIMPs in aortic extracts obtained from WHHL rabbits on an HC-diet. (d) Quantification of TIMP levels by densitometric analysis in aortic extracts obtained from WHHL rabbits on an HC-diet $\left(n=3\right.$ experiments, $\left.{ }^{*} P<0.05,{ }^{* *} P<0.01\right)$.

does not affect blood pressure. ${ }^{13,24,25}$ Therefore, it is reasonable to conclude that the inhibition of atherosclerosis progression induced by PPS treatment in WHHL rabbits is not mediated by a reduction of blood pressure levels.

The use of heparin and heparin-like molecules has been previously proposed as a treatment for atherosclerosis. ${ }^{1} \mathrm{How}-$ ever, the requirement for parenteral administration limits their use for this indication, a limitation that does not apply to PPS. Oral PPS has been widely used for treating interstitial cystitis. ${ }^{12}$ It has very few toxic side effects, even when administered for prolonged periods of time. ${ }^{26}$ PPS treatment prevents the development of glomerular and vascular lesions and tubulointerstitial inflammation and fibrosis in streptozotocin-induced diabetes, ${ }^{27} \mathrm{bGH}$ transgenic mice, ${ }^{27}$ and rats with cyclosporin A nephropathy ${ }^{28}$ or $5 / 6$ nephrectomy, ${ }^{13}$ reduces the symptoms of inflammatory arthritis, ${ }^{29}$ and decreases infarct size in an experimental myocardial ischemia/reperfusion injury model. ${ }^{30}$

The precise mechanism by which PPS achieves its protective effects has not been previously elucidated. We found that atherosclerotic plaques in PPS-treated WHHL rabbits contained fewer macrophages than those in watertreated controls. Others showed that PPS and heparin inhibit activation of the complement cascade, ${ }^{31}$ binds or displaces inflammatory cytokines, ${ }^{32}$ reduces NF- $\kappa$ B activation, ${ }^{33}$ scavenges free radicals, ${ }^{31}$ and reduces neutrophil adhesion and infiltration. ${ }^{30}$ These mechanisms can directly contribute to reduced macrophage recruitment and improved plaque development and stability.

We found that PPS treatment increased atherosclerotic plaque collagen content. As we have previously shown that PPS modulates cell proliferation, and the synthesis and accumulation of extracellular matrix ${ }^{14,15,27}$ we focused on MMP and TIMP activities. Net MMP-2/MMP-9 activity, evaluated using a synthetic colorimetric substrate, was significantly decreased in aortic extracts of PPS-treated animals. Moreover, MMP-2 activity and TIMPs, assessed by zymography and reverse zymography, respectively, were elevated in the aortic wall of PPS-treated animals. MMP and TIMP activity have emerged as important determinants of the atherosclerotic process and of vascular responses to injury. ${ }^{7-11}$ Increased amounts of several MMPs, including MMP-1, - -3, -8, and -9 , have been reported in mouse and rabbit atherosclerotic plaques and in the rupture-prone shoulder region of human atherosclerotic plaques. ${ }^{7-9,34,35}$ In particular, MMP-9 activity has been associated with the presence of macrophages, a marker for plaques vulnerable to rupture, and is enhanced in foam cells derived from the 

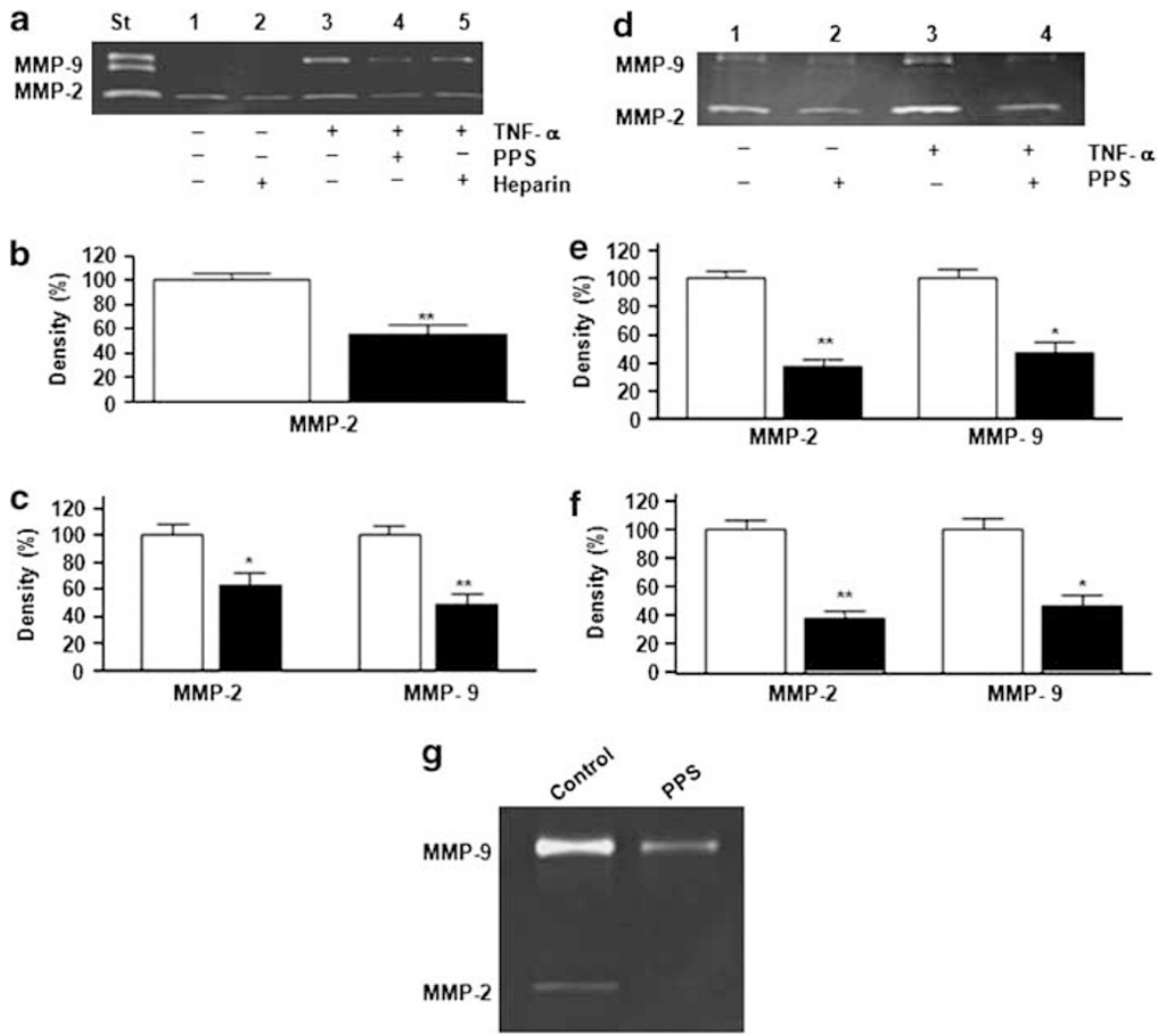

Figure 4 Matrix metalloproteinase (MMP) activity in monocytes-macrophages. Human pro-monocytic U937 cells or human peripheral blood-derived monocytes (PBMs) in RPMI medium supplemented with $10 \%$ fetal bovine serum (FBS) were stimulated with $10 \mathrm{ng} / \mathrm{ml}$ tumor necrosis factor $\alpha$ (TNF $\alpha$ ), in the presence or absence of pentosan polysulfate (PPS) $(100 \mu \mathrm{g} / \mathrm{ml})$ or heparin $(100 \mu \mathrm{g} / \mathrm{ml})$, incubated at $37^{\circ} \mathrm{C}$ for $3 \mathrm{~h}$, and then in $0.1 \%$ bovine serum albumin (BSA)-serum-free medium for $16-18 \mathrm{~h}$, as detailed in the Materials and Methods section. (a) Representative zymographic analysis of U937 cell supernatants. (b) MMP-2 activity was quantified by densitometry in supernatants of unstimulated U937 cells. Open bar, no treatment; filled bar, treatment with $100 \mu \mathrm{g} / \mathrm{ml}$ PPS. Data are expressed as the percent of control (unstimulated U937 cells). Shown are mean \pm s.e.m. of five independent experiments. ${ }^{*} P<<0.01$. (c) MMP-2 and MMP-9 activities were quantified by densitometry in supernatants of U937 cells stimulated with $10 \mathrm{ng} / \mathrm{ml} \mathrm{TNF} \alpha$. Open bar, no treatment; filled bar, treatment with $100 \mu \mathrm{g} / \mathrm{ml}$ PPS. Data are expressed as the percent of control $(10 \mathrm{ng} / \mathrm{ml} \mathrm{TNF} \alpha$-stimulated U937 cells). Shown are mean \pm s.e.m. of five independent experiments. ${ }^{*} P<0.05,{ }^{*} P<0.01$. (d) Representative zymographic analysis of supernatants from human PBMs.

(e) Quantification of MMP-2 and MMP-9 activities by densitometric analysis in the supernatants of unstimulated human PBMs, in the absence (open bars) or presence (filled bars) of $100 \mu \mathrm{g} / \mathrm{ml} \mathrm{PPS}$, expressed as the percent of control (unstimulated human PBMs). Shown are mean \pm s.e.m. of three independent experiments. ${ }^{*} P<0.05,{ }^{*} P<<0.01$. (f) MMP-2 and MMP-9 activities were quantified by densitometry in the supernatants of human PBMs stimulated with $10 \mathrm{ng} / \mathrm{ml} \mathrm{TNF} \alpha$, in the absence (open bars) or presence (filled bars) of $100 \mu \mathrm{g} / \mathrm{ml} \mathrm{PPS}$, expressed as the percent of control (10 $\mathrm{ng} / \mathrm{ml}$ TNF $\alpha$-stimulated human PBMs). (g) Effect of in vivo treatment with PPS on MMP activity in murine peritoneal-elicited macrophages: representative zymographic analysis of supernatants from peritoneal macrophages derived from mice treated orally with PPS (100 mg/kg body weight (BW)) for the previous 5-6 days and stimulated in vitro with $10 \mathrm{ng} / \mathrm{ml} \mathrm{TNF} \alpha$, compared with macrophages from mice treated with water (Control).

aortas of cholesterol-fed rabbits. ${ }^{7-11}$ In addition, adenovirusmediated MMP-9 overexpression produced instability of advanced plaques in ApoE-null mice, ${ }^{36}$ and the overexpression of a mutated fully-autoactivated form of MMP-9 in macrophages induced high levels of plaque instability. ${ }^{37}$ However, not all MMPs are markers for plaque inflammation; for instance, the levels of MMP-2 are increased in fibrous rather than atheromatous human carotid plaques, ${ }^{35}$ and increased MMP-2 activity has been associated mainly with smooth muscle cells and hence with plaque stability. ${ }^{35}$ Insights into the role of MMPs and TIMPs have been obtained from transgenic and knockout studies conducted in animal models of atherosclerosis. Although MMP-2-null mice show reduced accumulation of vascular smooth muscle cells within plaques, suggesting less plaque stability, ${ }^{38}$ genetic ablation of MMP-9 decreased plaque size, macrophage infiltration, and elastin breaks. ${ }^{39}$ Conversely, systemic adenovirus-mediated gene transfer of TIMP-1 or TIMP-2 improved plaque stability ${ }^{40,41}$ and prevented the progression of established brachiocephalic artery plaques. ${ }^{40}$ Moreover, TIMP-1-null mice showed increased macrophage intraplaque infiltration and higher destruction of medial elastin layers. ${ }^{42,43}$ Taken together, these results are consistent with the hypothesis of different roles of the various MMPs in the pathogenesis of atherosclerotic plaque progression. Some MMPs, in particular MMP-2, favor smooth muscle cell 
a

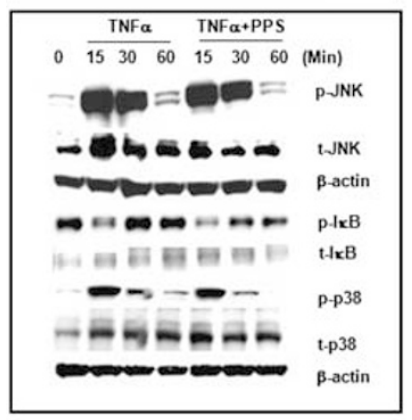

b

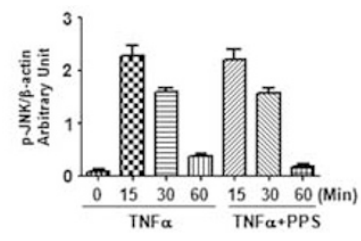

d

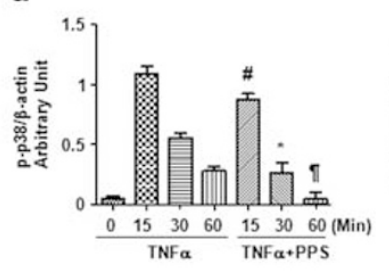

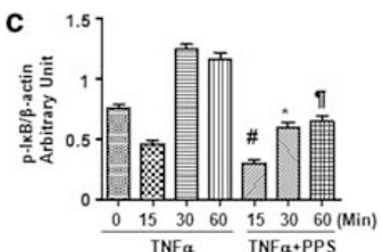

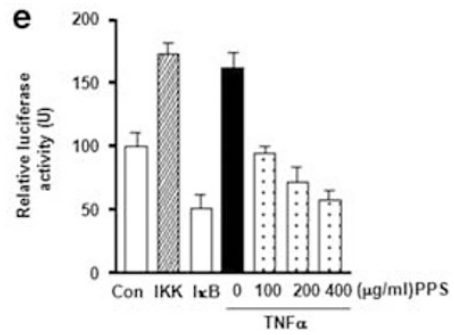

Figure 5 Modulation of mitogen-activated protein kinase (MAPK) and nuclear factor- $\kappa$ B (NF- $\kappa$ B) activation in RAW cells. (a) RAW cells were treated with tumor necrosis factor $\alpha$ (TNF $\alpha)(10 \mathrm{ng} / \mathrm{ml})$ in the presence or absence of pentosan polysulfate (PPS) (400 $\mu \mathrm{g} / \mathrm{ml})$ and phosphorylated, and total JNK, $\mathrm{I}_{\kappa} \mathrm{B}$, and $\mathrm{p} 38$ levels were determined by western blots. The same membranes were probed with $\beta$-actin to assess protein loading. Relative expression of $\mathrm{p}$-JNK, $\mathrm{p}-\mathrm{I} \kappa \mathrm{B}, \mathrm{p}$-p38 to $\beta$-actin (b-d, respectively; ${ }^{\#} P<0.05$ vs TNF $\alpha 15$ min; ${ }^{\star} P<0.05$ vs TNF $\alpha 30$ min; ${ }^{\circ} P<0.05$ vs TNF $\alpha 60$ min). (d) NF- $\kappa \mathrm{B}$ transcription activity was examined by transfecting macrophages with an NF- $\kappa$ B luciferase reporter together with a $\beta$-gal plasmid. Controls included cells transfected with IKK (dashed column) and I $\kappa$ B (white column). TNF $\alpha(10 \mathrm{ng} / \mathrm{ml})$ was added to reporter-transfected cells together with or without increasing concentrations $(100-400 \mu \mathrm{g} / \mathrm{ml})$ of PPS.

migration and fibrous cap formation, thus promoting plaque stability. Whereas others, including activated MMP-9, are involved in matrix degradation or enhancement of intraplaque inflammation, factors that are associated with plaque rupture. Herein, we found that reduced progression of atherosclerotic lesions in the aortas of PPS-treated WHHL rabbits is associated with decreased net collagenolytic activity and increased MMP-2 and TIMP activities within the aortic wall. These findings are consistent with the conclusion that increased collagen deposition is a feature accompanying reduced progression of atherosclerotic lesions induced by PPS treatment. This suggests that PPS-induced MMP-2 and TIMP overexpression within the plaque may contribute to plaque stabilization.

Previous reports correlated increased MMP activity by monocyte-macrophages to the development of acute complications such as plaque rupture and thrombosis. ${ }^{5-10,33}$ We found that PPS inhibited both MMP-2 and MMP-9 enzymatic activities in two types of human monocytes, a promonocytic cell line (U937 cells) and PBMs from normal volunteers. To further confirm this hypothesis, we studied MMP activity in elicited peritoneal macrophages derived from mice treated orally with PPS. In these animals, TNF $\alpha$ stimulated MMP activity was significantly decreased after PPS treatment compared with control animals, suggesting that this mechanism may be present in vivo. As the concentrations used for the in vitro experiments were close to the plasma levels reached in vivo after oral administration of PPS, ${ }^{27}$ this compound may have therapeutic use in humans in these disease processes. Moreover, the inhibitory activity of PPS on MMPs was still significant when the drug was administered up to $3 \mathrm{~h}$ after $\mathrm{TNF} \alpha$ stimulation.
It has been previously shown that inflammatory mediators, such as $\mathrm{TNF} \alpha$, play an active role in atherosclerosis progression. An important mechanism by which $\mathrm{TNF} \alpha$ increases inflammation is via upregulation of proinflammatory genes in macrophages. ${ }^{44}$ Since we found that PPS suppressed $\mathrm{TNF} \alpha$-stimulated $\mathrm{I} \kappa \mathrm{B}$ phosphorylation, NF- $\kappa \mathrm{B}$ transcription, and p38 phosphorylation, it is possible that PPS may directly decrease TNF $\alpha$-induced NF- $\kappa$ B and AP- 1 activities. The finding that PPS decreases TNF $\alpha$-stimulated iNOS, MCP-1, ICAM-1, and CXCL-1 mRNA expression in renal proximal tubular cells and podocytes via the inhibition of $\mathrm{NF}-\kappa \mathrm{B}$ indirectly supports this reasoning.

Thus, the beneficial effects of PPS on established atherosclerotic lesions may include stabilization of the amount of collagen in plaques mediated by modulation of MMP and TIMP activities, reduction of macrophage infiltration into the atherosclerotic plaque, and inhibition of inflammation in monocytes/macrophages exemplified by decreased MMP activity, NF- $\kappa \mathrm{B}$ activation, and p38 phosphorylation.

PPS also reduces binding of acetylated low-density lipoproteins to endothelial cells, ${ }^{45}$ and selectively inactivates several heparin-binding growth factors. ${ }^{46}$ Furthermore, PPS is both negatively charged and hydrophilic, two properties promoting its localization to the endothelial cell surface and preservation of the glycocalyx 'shield'.

In conclusion, we showed that the oral administration of PPS treatment retards the progression of established atherosclerosis in WHHL rabbits. The PPS effect appeared to be related to its ability to reduce inflammation, including macrophage infiltration and to regulate MMP and TIMP activities within the wall of the atherosclerotic aorta in a manner that favors collagen deposition, rather than collagen 
degradation. These properties may promote plaque stability. PPS treatment increased MMP-2 and TIMP activities within the atherosclerotic plaque, while it inhibited MMP-2 and MMP-9 activities in monocytes/macrophages. Further studies are required to assess the relevance of these observations to treatment of patients with established atherosclerosis.

\section{ACKNOWLEDGEMENTS}

Funding was provided by a Cooperative Research and Development Agreement between the NIDDK/NIH, Bethesda, MD, USA and the IVAX Pharmaceuticals, Miami, FL, USA. Special thanks to Pedro José Fernandez for technical support.

\section{DISCLOSURE/CONFLICT OF INTEREST}

The authors declare no conflict of interest.

1. Engelberg $\mathrm{H}$. Actions of heparin in the atherosclerotic process. Pharmacol Rev 1996;48:327-352.

2. Rogers C, Welt FG, Karnovsky MJ, et al. Monocyte recruitment and neointimal hyperplasia in rabbits. Coupled inhibitory effects of heparin. Arterioscler Thromb Vasc Biol 1996;16:1312-1318.

3. Kenagy RD, Nikkari ST, Welgus HG, et al. Heparin inhibits the induction of three matrix metalloproteinases (stromelysin, $92-\mathrm{kD}$ gelatinase, and collagenase) in primate arterial smooth muscle cells. J Clin Invest 1994;93:1987-1993.

4. Shibata Y, Abiko Y, Goto K, et al. Heparin stimulates the collagen synthesis in mineralized cultures of the osteoblast-like cell line, MC3T3-E1. Biochem Int 1992;28:335-344.

5. Libby $P$, Geng YJ, Aikawa M, et al. Macrophages and atherosclerotic plaque stability. Curr Opin Lipidol 1996;7:330-335.

6. Moreno PR, Falk E, Palacios IF, et al. Macrophage infiltration in acute coronary syndromes. Implications for plaque rupture. Circulation 1994;90:775-778.

7. Galis ZS, Khatri JJ. Matrix metalloproteinases in vascular remodeling and atherogenesis: the good, the bad, and the ugly. Circ Res 2002;90: 251-262.

8. Dollery CM, Libby P. Atherosclerosis and proteinase activation. Cardiovasc Res 2006;69:625-635.

9. Newby AC. Metalloproteinases and vulnerable atherosclerotic plaques. Trends Cardiovasc Med 2007;17:253-258.

10. Raffetto JD, Khalil RA. Matrix metalloproteinases and their inhibitors in vascular remodeling and vascular disease. Biochem Pharmacol 2008;75:346-359.

11. Newby AC, George SJ, Ismail Y, et al. Vulnerable atherosclerotic plaque metalloproteinases and foam cell phenotypes. Thromb Haemost 2009;101:1006-1011.

12. Davis EL, El Khoudary SR, Talbott EO, et al. Safety and efficacy of the use of intravesical and oral pentosan polysulfate sodium for interstitial cystitis: a randomized double-blind clinical trial. J Urol 2008;179:177-185.

13. Bobadilla NA, Tack I, Tapia E, et al. Pentosan polysulfate prevents glomerular hypertension and structural injury despite persisting hypertension in 5/6 nephrectomy rats. J Am Soc Nephrol 2001;12:2080-2087.

14. Elliot SJ, Striker LJ, Stetler-Stevenson WG, et al. Pentosan polysulfate decreases proliferation and net extracellular matrix production in mouse mesangial cells. J Am Soc Nephrol 1999;10:62-68.

15. Elliot SJ, Striker LJ, Connor E, et al. Pentosan polysulfate decreases proliferation and extracellular matrix deposition by vascular smooth muscle cells isolated from failed hemodialysis access grafts. Clin Nephrol 2000;54:121-127.

16. Elliot SJ, Zorn BH, McLeod DG, et al. Pentosan polysulfate decreases prostate smooth muscle proliferation and extracellular matrix turnover. Prostate Cancer Prostatic Dis 2003;6:138-142.

17. Shiomi M, Ito T, Tsukada $\mathrm{T}$, et al. Cell compositions of coronary and aortic atherosclerotic lesions in WHHL rabbits differ. An immunohistochemical study. Arterioscler Thromb 1994;14:931-937.

18. Iverius $\mathrm{PH}$, Brunzell JD. Human adipose tissue lipoprotein lipase: changes with feeding and relation to postheparin plasma enzyme. Am J Physiol 1985;249:E107-E114.
19. Shindo J, Ishibashi T, Yokoyama K, et al. Granulocyte-macrophage colony-stimulating factor prevents the progression of atherosclerosis via changes in the cellular and extracellular composition of atherosclerotic lesions in Watanabe heritable hyperlipidemic rabbits. Circulation 1999;99:2150-2156.

20. Valone FH, Epstein LB. Biphasic platelet-activating factor synthesis by human monocytes stimulated with IL-1-beta, tumor necrosis factor, or IFN-gamma. J Immunol 1988;141:3945-3950.

21. Camussi G, Bussolino F, Salvidio G, et al. Tumor necrosis factor/ cachectin stimulates peritoneal macrophages, polymorphonuclear neutrophils, and vascular endothelial cells to synthesize and release platelet-activating factor. J Exp Med 1987;166:1390-1404.

22. Jacot $T A$, Striker GE, Stetler-Stevenson $M$, et al. Mesangial cells from transgenic mice with progressive glomerulosclerosis exhibit stable, phenotypic changes including undetectable MMP-9 and increased type IV collagen. Lab Invest 1996;75:791-799.

23. Welgus HG, Campbell EJ, Cury JD, et al. Neutral metalloproteinases produced by human mononuclear phagocytes. Enzyme profile, regulation, and expression during cellular development. J Clin Invest 1990;86:1496-1502.

24. Herrera-Acosta J, Tapia E, Sánchez-Lozada LG, et al. Restoration of glomerular haemodynamics and renal injury independent of arterial hypertension in rats with subtotal renal ablation. J Hypertens Suppl 2002;20:S29-S35.

25. Guan Z, Fuller BS, Yamamoto T, et al. Pentosan polysulfate treatment preserves renal autoregulation in Ang II-infused hypertensive rats via normalization of P2X1 receptor activation. Am J Physiol Renal Physiol 2010;298:1276-1284.

26. Nickel JC, Forrest J, Barkin J, et al. Safety and efficacy of up to $900 \mathrm{mg} /$ day polysulfate sodium (elmiron) in patients with interstitial cystitis. Urology 2001;57:122-123.

27. Striker GE, Lupia E, Elliot S, et al. Glomerulosclerosis, arteriosclerosis, and vascular graft stenosis: treatment with oral heparinoids. Kidney Int Suppl 1997;63:S120-S123.

28. Schwedler SB, Bobadilla N, Striker LJ, et al. Pentosan polysulfate treatment reduces cyclosporine-induced nephropathy in salt-depleted rats. Transplantation 1999;68:1583-1588.

29. Smith MM, Ghosh P, Numata Y, et al. The effects of orally administered calcium pentosan polysulfate on inflammation and cartilage degradation produced in rabbit joints by intraarticular injection of a hyaluronate-polylysine complex. Arthritis Rheum 1994;37:125-136.

30. Tanhehco EJ, Kilgore KS, Naylor KB, et al. Reduction of myocardial infarct size after ischemia and reperfusion by the glycosaminoglycan pentosan polysulfate. J Cardiovasc Pharmacol 1999;34:153-161.

31. Kilgore KS, Naylor KB, Tanhehco EJ, et al. The semisynthetic polysaccharide pentosan polysulfate prevents complement-mediated myocardial injury in the rabbit perfused heart. J Pharmacol Exp Ther 1998;285:987-994.

32. Tanaka Y, Adams DH, Shaw S. Proteoglycans on endothelial cells present adhesion-inducing cytokines to leukocytes. Immunol Today 1993;14:111-115.

33. Sadhukhan PC, Tchetgen MB, Rackley RR, et al. Sodium pentosan polysulfate reduces urothelial responses to inflammatory stimuli via an indirect mechanism. J Urol 2002;168:289-292.

34. Sukhova GK, Schönbeck U, Rabkin E, et al. Evidence for increased collagenolysis by interstitial collagenases- 1 and -3 in vulnerable human atheromatous plaques. Circulation 1999;99:2503-2509.

35. Sluijter JP, Pulskens WP, Schoneveld $\mathrm{AH}$, et al. Matrix metalloproteinase 2 is associated with stable and matrix metalloproteinases 8 and 9 with vulnerable carotid atherosclerotic lesions: a study in human endarterectomy specimen pointing to a role for different extracellular matrix metalloproteinase inducer glycosylation forms. Stroke 2006;37:235-239.

36. de Nooijer R, Verkleij CJ, von der Thüsen $\mathrm{JH}$, et al. Lesional overexpression of matrix metalloproteinase- 9 promotes intraplaque hemorrhage in advanced lesions but not at earlier stages of atherogenesis. Arterioscler Thromb Vasc Biol 2006;26:340-346.

37. Gough PJ, Gomez IG, Wille PT, et al. Macrophage expression of active MMP-9 induces acute plaque disruption in apoE-deficient mice. J Clin Invest 2006;116:59-69.

38. Kuzuya M, Nakamura K, Sasaki T, et al. Effect of MMP-2 deficiency on atherosclerotic lesion formation in apoE-deficient mice. Arterioscler Thromb Vasc Biol 2006;26:1120-1125. 
39. Luttun A, Lutgens E, Manderveld A, et al. Loss of matrix metalloproteinase- 9 or matrix metalloproteinase-12 protects apolipoprotein E-deficient mice against atherosclerotic media destruction but differentially affects plaque growth. Circulation 2004;109:1408-1414.

40. Johnson JL, Baker AH, Oka $\mathrm{K}$, et al. Suppression of atherosclerotic plaque progression and instability by tissue inhibitor of metalloproteinase-2: involvement of macrophage migration and apoptosis. Circulation 2006;113:2435-2444.

41. Rouis M, Adamy C, Duverger N, et al. Adenovirus-mediated overexpression of tissue inhibitor of metalloproteinase-1 reduces atherosclerotic lesions in apolipoprotein $\mathrm{E}$ deficient mice. Circulation 1999;100:533-540.

42. Lemaitre V, Soloway PD, D'Armiento J. Increased medial degradation with pseudo-aneurysm formation in apolipoprotein E-knockout mice deficient in tissue inhibitor of metalloproteinases-1. Circulation 2003; 107:333-338.

43. Silence J, Collen D, Lijnen HR. Reduced atherosclerotic plaque but enhanced aneurysm formation in mice with inactivation of the tissue inhibitor of metalloproteinase-1 (TIMP-1) gene. Circ Res 2002;90: 897-903.

44. Yan C, Boyd DD. Regulation of matrix metalloproteinase gene expression. J Cell Physiol 2007;211:19-26.

45. Deli MA, Abraham CS, Takahata $\mathrm{H}$, et al. Pentosan polysulfate regulates scavenger receptor-mediated, but not fluid-phase, endocytosis in immortalized cerebral endothelial cells. Cell Mol Neurobiol 2000;20:731-745.

46. Zugmaier G, Favoni R, Jaeger R, et al. Polysulfated heparinoids selectively inactivate heparin-binding angiogenesis factors. Ann NY Acad Sci 1999;886:243-248. 